\title{
Filosofía y Antropología
}

Cuando se tiene que hablar de las relaciones entre filosofía y antropología, lo primero que hay que decir al respecto es que con frecuencia estas relaciones han sido analizadas interesadamente, negando las cualidades de una u otra disciplina según el campo con el que se identificara el analista en cuestión. Las consecuencias de esta actitud son de todos conocidas: los esfuerzos que debían dedicarse a desarrollar cada una de estas materias han sido malgastados en poner de manifiesto las carencias de la otra. Creo que esta postura es un error; ningún saber se puede construir sobre la base de la negación de los demás, pero, además, apenas puede ocultar lo que a estas alturas debería ser obvio: que a pesar de todos los obstáculos, la antropología y la filosofía están destinadas a entenderse. Para defender esta posición, voy a dedicar lo que sigue a hablar de la antropología filosófica, materia donde ambos dominios deberían encontrar su mayor punto de convergencia y donde, por el contrario, son frecuentes las divergencias. Entenderemos ésta desde dos puntos de vista: como fundamento ontológico de la antropología cultural, y como planteamiento ético acerca del sentido de la vida humana. Trataremos, más adelante, de aquellos otros lugares donde resulta más necesaria la colaboración entre antropología y filosofía, y que no son otros que la historia y la epistemología de la antropología.

II

Para comenzar, podemos decir de la Antropología filosófica que no existe pleno acuerdo en torno a qué sea ésta, ni sobre su objeto. Esta dificultad no ha escapado a quien ha tratado de señalar su propia historia:

Es evidente que el intento de trazar, aunque sólo sea en líneas generales, los rasgos fundamentales del desarrollo histórico de la Antropología filosófica propiamente dicha debería comenzar con la determinación de lo que se entiende por tal. Es decir, más claramente expresado, no sólo habría que determinar desde un principio el concepto de Antropología filosófica, sino también, y sobre todo, 
su contenido temático, así como su extensión y alcance, es decir, el conjunto de cuestiones que son de su propia y exclusiva competencia. Esto sin embargo supondría introducirse en la problemática más difícil con que necesariamente se enfrenta la Antropología filosófica actual (Rodríguez Molinero, 1977: 12-13).

La definición variará, por tanto, según los autores a los que se recurra; en general, podemos ver que la antropología filosófica se entiende como:

a) una disciplina que se ocupa de la idea de hombre presente en o deducible de la filosofía general de cada autor;

b) una meditación de carácter filosófico sobre la naturaleza del hombre, y/o

c) una reflexión sobre el ser humano que utiliza los datos de distintas ciencias para investigar en qué consiste la esencia humana.

Cualquiera que sea la alternativa que se escoja, debe quedar claro que estamos ante una disciplina que se enmarca en el ámbito de la filosofía. Esta obviedad, pues así debe calificarse tener que advertir de la pertenencia a la filosofía de una disciplina cuyo nombre incluye a ésta como característica esencial, no parece ser tenida en cuenta en numerosas ocasiones, sobre todo, por parte de aquéllos que le exigen el cumplimiento de unos patrones en todo ajenos a los que son propios de la reflexión filosófica. Volveremos a tratar esta cuestión más adelante, pero era conveniente hacerla explícita para evitar las confusiones en las que algunos incurren. Ahora, vamos a decir algunas palabras sobre las opciones señaladas; el grado de compromiso con cada una de ellas no resulta fácil de delimitar en los distintos pensadores, y, por supuesto, todas deben considerarse legítimas. Sin embargo, las consecuencias varían según nos inclinemos de manera aislada por una u otra. La primera alternativa considera a la antropología filosófica como una parte de la filosofía de cada pensador. Desde esta perspectiva sería correcto hablar de la existencia de una idea de hombre presente desde los orígenes de la filosofía, por más que muchas veces, al no mostrarse como un saber explícito, tendríamos que esforzarnos en desentrañar lo que sólo aparece inmerso en otras partes del discurso filosófico.

La segunda alternativa consiste en una meditación de carácter filosófico sobre la naturaleza del hombre; sus orígenes pueden situarse en el Renacimiento, con la proliferación de tratados sobre el hombre cuyo tema preferente era su dignidad - Pico della Mirandola-, el hombre como microcosmos -Nicolás de Cusa-, etc. Lo que estas obras pretendían poner de manifiesto era la posición peculiar del ser humano frente al resto de los seres de la creación. En ellas no era necesario esforzarse por sacar 
a la luz un contenido más o menos implícito dentro de una filosofía general, sino que el tema del hombre mismo constituía su centro de reflexión; si acaso, eran el resto de los temas filosóficos tradicionales los que se presentaban incluidos, como presupuestos de tipo metafísico, ontológico o moral, dentro de esa reflexión.

La tercera de las opciones anteriores pretende ser una meditación sobre la esencia humana a partir de los datos que proporcionan las distintas ciencias. Es tal vez el concepto teórico más actual de antropología filosófica, pero no siempre se ha llevado a la práctica con el debido respeto hacia las ciencias del hombre. Por desgracia, en la mayor parte de los estudiosos de la antropología filosófica no es que haya pesado más lo que tenían de filósofos que lo que pudieran tener de antropólogos, sino que han ignorado sistemáticamente las aportaciones y principios básicos de la antropología. De ahí proceden algunas de las divergencias que podemos apreciar entre los que se consideran antropólogos (sociales o culturales) y los antropólogos filosóficos.

De este último aspecto se desprende lo que ya advertí al inicio de este texto, a saber, que el grado de compromiso con cada una de las opciones a las que hemos aludido no resulta fácil de delimitar en los distintos pensadores. Sin duda, las dos últimas tienden a confundirse, pues, cuando los modernos antropólogos filosóficos prescinden de las aportaciones de las ciencias humanas, lo único que diferencia su tarea de lo que los filósofos hacían durante el Renacimiento, es la actualidad de la filosofía que está en la raíz de su meditación sobre el hombre, pero no la caracterización general de sus contenidos y conclusiones. Quiero decir con ello que una meditación sobre el hombre que parta de la metafísica, la ontología, la moral, o de cualquier otra parte de la filosofía, no se diferencia en principio mucho de una reflexión que a partir del hombre intente llegar a conclusiones de tipo metafísico, ontológico o moral. La filosofía que inspiraba los escritos renacentistas ha cambiado en nuestra época, pero si se ignoran las aportaciones de otras ciencias durante todo el tiempo transcurrido, de bien poco nos sirve ser conscientes de ello. Sólo a la contra, esto es, para demostrar su vileza, es posible imaginar en la actualidad que alguien se atreva a escribir sobre la "dignidad del hombre", cuando las mayores atrocidades cometidas por los seres vivos tanto contra sus semejantes como contra la naturaleza que los alberga se deben a la especie humana; tampoco es fácil pensar a los individuos como microcosmos que representan a pequeña escala lo que el macrocosmos o el absoluto divino son en otra dimensión, tal vez porque de esa identificación con lo divino sólo se desprende intransigencia y restricciones para la autonomía de los demás. Pero esto, es decir, que el pensamiento se haga eco de una 
problemática filosófica actual, no es suficiente, hay que integrar los saberes que proporcionan las ciencias si se pretende cumplir el objetivo de hacer una filosofía que esté a la altura de los tiempos.

No es difícil apreciar que este proyecto acompaña a la antropología filosófica desde, al menos, el giro antropológico que le diera Kant. La defensa renacentista de la autonomía y peculiaridad del ser humano se constituye en un supuesto ilustrado, a partir del cual tiene sentido plantearse lo que el hombre es como raíz de todas las cuestiones que tradicionalmente han ocupado a la filosofía. Por tanto, lo que durante el Renacimiento empezó siendo un análisis del hombre desde presupuestos filosóficos de diferente tipo, acaba convirtiéndose durante la Ilustración en una reflexión sobre las capacidades y posibilidades del hombre en cada uno de esos dominios. De esta forma la moderna antropología filosófica se vincula a la problemática que introduce en la filosofía el pensamiento kantiano. Para Kant, el interés de la razón tanto especulativa como práctica se contiene en tres preguntas: 1) ¿qué puedo saber? 2) ¿qué debo hacer? y 3) ¿qué puedo esperar? Estas tres cuestiones se pueden recoger en una que las engloba: ¿qué es el hombre? No tiene sentido en este momento hacer una genealogía de autores que han continuado investigando en esta misma línea (Choza, 1985). Basta con señalar que en nuestro siglo probablemente sea Max Scheler (1970 [1928]) el autor que más ha contribuido a extender el término antropología filosófica dentro de la filosofía. Con él, la antropología filosófica se configura como una disciplina mediadora entre las ciencias positivas y la metafísica. Este sentido parece haberse impuesto mayoritariamente; hoy en día se admite la posibilidad de investigar la antropología filosófica de cualquier autor, es decir, se da por supuesta la validez de la primera de las opciones que hemos señalado, pero cobra fuerza la idea según la cual esta disciplina se relaciona tanto con las otras antropologías (cultural, física, etc.), y ciencias afines (sociología, biología, psicología, historia, etc.), como con los problemas de carácter ético y metafísico (véase "la pluralidad de direcciones antropológicas* a la que, con criterio excesivamente amplio, alude J. L. Rodríguez Molinero, 1977: 37-39). Sin duda un espíritu exigente encontraría falto de precisión un programa de estas características, pero eso no ha sido obstáculo para que numerosas obras posteriores a la de Scheler se hayan situado bajo esta rama de la filosofía. Las más prestigiosas desde un punto de vista internacional tal vez sean las de Helmut Plessner y Arnold Gehlen (1980), pero pueden destacarse otras de diferentes tendencias, como las investigaciones de Ernst Cassirer (1977), y la misma obra de Jean Paul Sartre (1970), cuyo existencialismo pretendía proporcionar al marxismo la antropología filosófica de la que en su opinión carecía aquél. 
Así, pues, la antropología filosófica, sin renunciar a su carácter filosófico, se presenta desde un principio como un proyecto de evidentes raíces antropológicas, si bien el concepto de antropología que subyace a las mismas posee claros tintes uniformadores y etnocéntricos. Kant se preocupa por la esencia del hombre, pero, de acuerdo con alguno de los dogmas de la Ilustración, entiende que en ésta no tienen cabida las diferencias culturales; sólo sus contemporáneos europeos, en tanto que máximos representantes de la razón, merecían ser tenidos en cuenta a la hora de definir qué sea el hombre. Esta actitud está presente en gran parte de la antropología filosófica (occidental); a este respecto, resulta paradigmática la crítica que Lévi-Strauss hace a Sartre en El pensamiento salvaje por sus afirmaciones sobre los "primitivos" en la Crítica de la razón dialéctica: "se necesita mucho egocentrismo y mucha ingenuidad para creer que el hombre está, por entero, refugiado en uno solo de los modos históricos o geográficos de su ser, siendo que la verdad del hombre reside en el sistema de sus diferencias y de sus propiedades comunes" (Lévi-Strauss, 1964: 360-361). Sin embargo, es muy difícil escapar de este tipo de críticas cuando un autor intenta decir algo más que cuatro tópicos acerca de la totalidad de la especie humana. El propio Lévi-Strauss es el objeto de la censura de Edmund Leach porque

oscila sin cesar, y de forma muy arriesgada, entre el estudio del hombre y el estudio de los hombres concretos. Cuando habla del hombre, el espíritu humano- se convierte entonces en el agente creador responsable del milagro de la cultura, y este espíritu humano es un aspecto del cerebro humano, propiedad común a todos los miembros de la especie homo sapiens. Pero cuando habla de pueblos concretos, se ve obligado a reificar una entidad de un tipo algo diferente (Leach, 1970: 14-15).

\section{III}

Incluso con esta breve introducción a la antropología filosófica que acabamos de realizar, no dejan de manifestarse algunos de los principales problemas que tiene planteados esta disciplina. En primer lugar, su propio ser. Sería demasiado cruel decir que la antropología filosófica se configura más como una asignatura que como una disciplina, pero, ciertamente, es claro que existe en el primer sentido, mientras que explicarla en el segundo no resulta del todo fácil. Con ello nos enfrentamos a una curiosa paradoja: frente a lo que suele ser habitual en otros campos de investigación, estamos ante un núcleo de conocimientos que primero han recibido un reconocimiento institucional, el cual se plasma en su inclusión 
como asignatura dentro de programas universitarios y en la creación de cátedras para impartirla, y con posterioridad se intenta definir cuál sea su objeto exacto. Este oscila según los distintos autores que consultemos, lo cual, si tenemos presente que estamos ante una disciplina de carácter filosófico, no debe inducir a escándalo. Sin embargo, a pesar de estos desacuerdos, podemos desechar algunos malentendidos. Cuando se habla de antropología filosófica hay que olvidarse de la idea de una antropología integral o general, es decir, no hay que confundir la antropología filosófica con el conjunto de las ciencias que se ocupan del hombre ni con la totalidad de los conocimientos que éstas pudieran compartir. A este respecto quisiera llamar la atención sobre lo siguiente: si fuera posible compendiar el saber que proporcionan las distintas ciencias humanas en una teoría general cuyos elementos no entraran en contradicción, como de hecho ocurre a menudo, o reunir los datos que proporcionan acerca del hombre, seguiría existiendo una parte importante de lo que éste es que escaparía a esa teoría general o a esa amalgama de conocimientos. Al decir que la antropología cultural deja fuera de sus investigaciones ciertas parcelas humanas no se está haciendo referencia a la insuficiencia epistemológica, tantas veces puesta de manifiesto, de las ciencias sociales. Se puede aceptar que el estado preparadigmático o no cerrado de la antropología cultural actual dará paso con el transcurso del tiempo a una ciencia paradigmática o categorial, sin que ello implique que la afirmación anterior deba ser modificada. Aunque se acepte que las ciencias sociales deben tener su propio estatuto epistemológico independiente de las ciencias naturales, o que, por el contrario, deben llegar a adquirir éste si quieren convertirse en auténticas ciencias, lo cierto es que habrá un conocimiento del hombre que escapará a su dominio. La antropología filosófica tendrá como objeto de estudio esa parcela de conocimiento sobre el ser humano que escapa a las posibilidades de investigación de las ciencias del hombre, cualquiera que sea el nivel de exigencia epistemológica que éstas posean.

La antropología filosófica no aspira a culminar el edificio del conocimiento construido sobre los cimientos que forman las ciencias humanas, sino a ocupar en los límites de éste el lugar que le corresponde. Estos límites se definen desde una posición doble: como fundamento ontológico, la antropología filosófica debe proporcionar a la antropología cultural su objeto de estudio, o lo que es lo mismo, será la antropología filosófica la que defina al ser humano que debe estudiar la antropología cultural. Muchos antropólogos no sienten la necesidad de esta fundamentación ontológica cuando afrontan el estudio de otras culturas, pero de hecho están haciendo uso de la misma. La única diferencia entre lo que hacen 
y la antropología filosófica fundamentadora a la que aludimos reside en que en el primer caso se da una utilización implícita de la misma, mientras que en el segundo se debe discutir explícitamente acerca de ella. Puede que no hagamos un problema del reconocimiento de los seres humanos que vamos a estudiar como antropólogos culturales, pero no cabe duda de que el conocimiento que vamos a obtener está enraizado en un conocimiento previo que exige ser analizado. Se trata, por tanto, de una tarea preparatoria, de una introducción o propedéutica; sin embargo, en la medida en que ésta debe ser fundamentadora de lo que entendemos por hombre, es legítimo decir que estamos ante una ontología.

No creo necesario aludir a que esta definición ontológica del hombre no puede quedarse en la constatación de su naturaleza biológica, puesto que en ningún caso puede ésta explicar lo que pudiéramos denominar su "esenciam. No es la biología la que define al hombre, sino la interacción de su organismo con el medio. La biología puede significar un umbral definitivo para algunas especies animales, pero en el ser humano, ésta es sólo una parte de una relación dialéctica que tiene como fruto la cultura. La importancia de ésta obliga, además, a superar el obstáculo que supone interpretar al ser humano como un ser concluso, de manera semejante a como lo entendieron los pensadores griegos en el pasado (García, 1979: 259), y, con ellos, buena parte de la antropología filosófica posterior (San Martín, 1988: 43 y ss.). El hombre, por otra parte, no existe fuera de un tiempo concreto en el que adquiere sentido su vida; esto es, el hombre no puede ser pensado como un sujeto intemporal. Ninguna sociedad permanece estable, y el entendimiento de los individuos que la componen exige el reconocimiento de este hecho. No existirá una teoría del hombre o, si se quiere, una antropología filosófica, sino tantas como momentos de la historia humana se quiera analizar. Por otra parte, a la hora de definir al hombre hay que evitar imponer las características de un grupo humano, por amplio o importante que éste pueda ser respecto al resto, como normas de conducta válidas para la totalidad de la especie. Al ser la cultura un constitutivo esencial del ser humano, se puede decir que éste es un sujeto no acabado, proyectivo, porque ningún estado cultural en el que se encuentre se puede considerar definitivo; pero, además, su diversidad y capacidad de adaptación excede cualquier posibilidad de elevar a modelo para la especie las pautas culturales de un grupo concreto de la misma. Así pues, la definición del hombre que intente servir de fundamento ontológico a las investigaciones sobre los diferentes grupos humanos deberá tener presentes las necesidades que impone su naturaleza biológica, su carácter proyectivo, la temporalidad en la que se inscribe, su constitución esencialmente cultural, y la variabilidad de respuestas que ésta ha provocado. 
Esta sería una primera tarea de la antropología filosófica. Pero hemos dicho que la antropología filosófica aspira a ocupar los límites del edificio que constituyen los conocimientos de las ciencias humanas. Además de lograr una fundamentación ontológica, debe ocuparse de establecer un criterio ético. No hay que olvidar que la antropología cultural investiga las diferencias y semejanzas entre las distintas culturas; el estudio de los comportamientos de los seres humanos que integran éstas se realiza dentro del respeto a las formas de vida diferentes a las del estudioso u observador. La antropología cultural, en definitiva, está directamente vinculada al relativismo cultural. Esto significa que el antropólogo en su afán por comprender a las otras culturas intenta prescindir de los valores morales de su propia sociedad. No basta, sin embargo, con comprender el valor de las distintas conductas y tolerarlas, es necesario, además, hacer uso de algún criterio ético que permita establecer qué aspectos de la vida de los otros deben ser incorporados no sólo a nuestra propia cultura, sino a los valores fundamentales de la humanidad. Si la antropología cultural quiere saber cómo vive el hombre en otras culturas, la antropología filosófica desea utilizar estos conocimientos para recuperar o alcanzar comportamientos y hábitos que habíamos olvidado o que desconocíamos en nuestra propia cultura. Ahora bien, el objetivo último no es servirnos de ello para nuestra propia cultura, pues, si así fuera, ésta volvería a configurarse como el modelo al cual deben tener como referencia el resto de los modos de vida; recuperar para nuestra cultura lo que nos ofrecen las otras culturas es sólo un primer paso. La finalidad última de la antropología filosófica a este respecto será construir una idea válida para la humanidad. De esta forma cobra plena significación la raíz dialéctica y comparativa que se encuentra en la génesis de la antropología cultural: conocer a los otros para conocernos mejor nosotros mismos, y conocer lo propio para comprender mejor a los otros.

En definitiva, al estudio de las diferencias y semejanzas entre los distintos grupos humanos y sus culturas, que la antropología cultural afronta, añade la antropología filosófica la pregunta por el sentido de la vida humana, esto es, el esfuerzo de interpretar al hombre como sujeto que conoce, como sujeto ético y como sujeto metafísico. Por eso decía anteriormente que el campo de estudio del que se ocupa la antropología filosófica escapa a las posibilidades de investigación de las ciencias del hombre, lo cual no quiere decir que prescinda de sus enseñanzas. Cualquiera de estas dimensiones no se da en abstracto, ni siquiera basta con decir que tienen lugar dentro de determinadas circunstancias, pues, como hemos dicho, si algo enseña la antropología cultural, es que la cultura no es sólo la circunstancia donde se desarrolla la vida del hombre, sino, muy 
por encima, lo que le permite serlo. Por tanto, si queremos situar el planteamiento kantiano sobre el hombre dentro de la perspectiva que imponen las aportaciones de las ciencias humanas de nuestra época, y, en concreto, de las diferencias culturales que ha puesto de manifiesto la antropología cultural, tendremos que tomar como punto de partida y tener siempre presentes en nuestra reflexión los distintos modos de ser humano. Pasó la época en la que el modelo europeo y occidental de hombre podía ser presentado como modelo a imitar por el resto de los grupos humanos.

IV

Una vez que hemos definido qué es la antropología filosófica y cuáles son sus campos de interés, estamos en condiciones de enfrentarnos a algunas de las críticas de las que ha sido objeto. El lugar más importante entre éstas debe ocuparlo la acusación de abstracción y acientificidad. Ha sido formulada en numerosas ocasiones, pero aquí vamos a reproducir tan sólo una de ellas:

Un pensar en abstracto sobre el hombre no puede ser más que ideología, no ciencia, y eso es lo que se imparte en casi todas las materias de "Antropología. de dicha especialidad, al estar a cargo no de antropólogos - como sería de esperar en pura lógica- sino de filósofos (Moreno, 1979: 12).

Por lo que respecta a la primera acusación, la abstracción que introduce la antropología filosófica, hay que admitir que la imagen del hombre que ha tratado de definir ésta ha prescindido de su materialidad, de los atributos que por no considerarse estrictamente vinculados a su "esencia", se conceptuaban ajenos a éste. Recogiendo el viejo dilema cartesiano, la antropología filosófica ha entendido que el hombre se definía como una res cogitans más que como una res extensa, como si fuera posible y necesario separar ambas sustancias. Pero, además, ha infravalorado la vinculación del hombre con su temporalidad; no ha estudiado a éste en su contexto, dentro de las circunstancias históricas concretas en las que vivía. El resultado ha sido, ciertamente, un pensar abstracto sobre el hombre. Sin embargo, en la frase citada parece decirse algo más cuando se afirma que este tipo de pensar no puede ser más que ideología, no ciencia, máxime si se tiene en cuenta que previamente se ha advertido que -cuando nos referimos a los conceptos de 'ideología' e 'ideológico' lo hacemos en el sentido de 'visión deformada, acientífica, encubridora de la verdadera esencia de las cosas'. (Moreno, 1979: 219, nota 1). Es decir, en última instancia, la abstracción que introduce la antropología filosófica 
no viene a ser tanto un problema que afecta a la forma de afrontar su objeto de estudio como a una insuficiencia de sus resultados. Ante esta conclusión no cabe menos que hacer un cuestionamiento $a b$ initio de la misma: ¿el único saber legítimo es el saber científico? Sin duda el autor de este texto no puede mantener una propuesta semejante, puesto que con anterioridad ha confesado que la antropología (cultural) todavía no es una disciplina científica en sentido estricto:

la crisis actual de la Antropología es la que podrá permitir la existencia en el futuro de una verdadera ciencia antropológica, ya que sólo con la puesta en cuestión de las bases del modo de producción dentro del cual ha surgido y se ha desarrollado la disciplina podrá ésta liberarse de su carácter todavía ampliamente ideológico y acceder plenamente a la categoría científica. La crisis actual de la Antropología no es, pues, una desgracia que pone en peligro su existencia, sino el medio por el cual puede consolidarse una verdadera ciencia del hombre y de la sociedad (Moreno, 1979: 7-8).

Probablemente, lo que se quiere mantener al aludir al carácter científico que la antropología cultural puede adquirir en el futuro es la deseabilidad de éste, pero de ello no se desprende la desestimación de todo discurso que no sea (todavía o nunca) científico. La postura contraria supondría volver a un positivismo difícilmente aceptable hoy en día. No se puede ignorar que la validez del pensamiento se define en términos de racionalidad, no de cientificidad, requisito éste por el que sólo se rigen determinadas disciplinas.

Sin embargo, no es sólo que esta crítica pierda su radicalidad por aplicarse de forma restringida a un ámbito (el de la antropología filosófica), y no a otro (el de la antropología cultural); ni que confunda la racionalidad que debe acompañar a todo pensamiento con la cientificidad que sólo es propia de algunos; es que, además, su aplicación a la antropología filosófica se realiza desde el supuesto de la pertenencia de ésta a la antropología (cultural), lo que en absoluto es opinión unánime de quienes se ocupan de esta materia. Tal vez, el problema último al que quiere aludir I. Moreno, disfrazándolo bajo la superestructura de la exigencia epistemológica, no sea otro que éste: la antropología filosófica es impartida por filósofos cuando debería serlo por antropólogos (op. cit.: 12). No es ocioso recordar a este respecto que la antropología filosófica goza de aceptación general fuera de nuestro país como disciplina filosófica, la cual no se opone a la existencia de la antropología cultural. Con la institucionalización de ambas disciplinas en España es donde surge la polémica. A comienzos de la década de los setenta, los nuevos planes de 
estudios de las facultades de Filosofía preveían la creación y provisión de plazas de antropología filosófica; este fue el camino por el que se abrirían paso en estas facultades un buen número de antropólogos de carácter social y cultural, así como los que entendían la materia desde un punto de vista más filosófico; entre los primeros, no fueron pocos los que hubieron de soportar arbitrariedades (incluyendo descalificaciones por parte de miembros de tribunales de oposiciones) a causa de la presunta inadecuación de sus curricula (de antropólogos sociales) para la asignatura (antropología filosófica) a la que optaban. Todavía hoy (1994), subsiste esta división académica dentro de la misma asignatura, si bien se tiende a cambiar su nombre por el de antropología social (o cultural) en aquellos casos en los que los contenidos transmitidos pertenecen a la etnología. Existen, no obstante, profesionales que al entender la materia como una reflexión filosófica a partir de los datos que proporcionan las distintas ciencias que investigan al hombre, y, especialmente, la antropología física, la antropología social y la etnohistoria, no encuentran obstáculo alguno para, bajo el nombre de antropología filosófica, dedicarse a la práctica de algunas vertientes de la antropología social y filosófica, generalmente, en los términos que hemos señalado con anterioridad. Lo que se quiere sostener con ello es que, desde el punto de vista de su objeto y método de estudio, ambas opciones no se oponen necesariamente, lo cual no es obstáculo para que surjan conflictos de intereses en casos concretos.

Así pues, negar a la antropología filosófica su carácter científico, no puede constituir una crítica fundamental desde el momento en que se admite que ésta es una disciplina filosófica. Esta parece ser la postura a la que ha llegado C. Esteva, quien, tras distinguir la antropología (cultural) de la filosofía, entendida como antropología filosófica, por el carácter científico de la primera (1972: 42 y ss.), reconoce que:

la antropología filosófica no presentaba dudas en cuanto a su estructura exclusivamente especulativa y de reflexión teórica, a la vez gnoseológica y ontológica del hombre. Para mí no admitía dudas la legitimidad de una antropología filosófica (1982: 17).

Por otra parte, el término "científico" es una fuente de confusión: si al utilizarlo se está presuponiendo que toda disciplina debe ser científica, en el sentido en que lo afirmaba el positivismo decimonónico, quien así lo asegura debería preocuparse más por el estatuto epistemológico de la antropología cultural; si, por el contrario, se quiere aludir a la racionalidad de toda argumentación, la antropología filosófica es tan racional como lo pueda ser cualquier otra reflexión teórica. 
Existe, no obstante, y con ello entramos en la segunda parte de nuestra exposición, una clara vinculación entre la antropología cultural y la filosofía, cuando ésta última adopta la forma de una teoría del conocimiento antropológico. La antropología filosófica entendida como epistemología tendrá como tarea fundamental analizar el campo de la antropología, delimitando dentro de éste las características de las diversas teorías existentes, definiendo sus límites y relaciones con otras disciplinas, y estudiando la validez de sus métodos.

Al ser la antropología cultural una ciencia preparadigmática, conviven dentro de la misma una serie de alternativas que compiten entre sí por imponer su concepto de la disciplina sobre el resto. Las concepciones de la antropología que llevan consigo cada uno de estos paradigmas son, en ocasiones, tan opuestas que un observador que los contemple puede llegar a dudar de que todos ellos tengan un núcleo de conocimientos en común. Cuando esta sensación se lleva al extremo de exagerar los desacuerdos por encima de los supuestos básicos compartidos, el resultado no es otro que la inexistencia de la antropología como disciplina global; su terreno pasa a ser ocupado por lo que se denomina disciplinas categoriales, tales como la antropología médica y la antropología biológica (Bueno, 1987: 190 y ss.; Ronzón, 1991). La cuestión que debe plantearse en estos casos es la siguiente: si la historia de la antropología es la historia de un fantasma gnoseológico porque no se puede hablar de un único concepto de antropología, ¿cuál es el criterio que permite hacer una historia crítica de la antropología con obras que aparentemente no comparten ningún elemento fundamental? En la práctica, dicho análisis se basa en el uso del término "antropología (Ronzón, 1991: 162), aunque sea con la finalidad de descubrir los distintos significados con que éste aparece. Pero si este término es reclamado como propio por distintas formas de entender la antropología (biológica, médica, criminal, etc.) será porque todas ellas comparten un núcleo de problemas comunes, aunque también disten de coincidir en otros muchos aspectos. En definitiva, y aplicado al caso de España, es muy posible que el concepto de antropología predominante durante el siglo XIX no coincida con el actual, y que tanto en aquél como en éste sea fácil encontrar múltiples desacuerdos entre las distintas tendencias, pero la existencia de un conjunto de obras que llevan entre su título la palabra "antropología. o que se reconocen pertenecientes a este campo, el conocimiento mutuo entre sus practicantes, la unión en sociedades similares -no es ocioso recordar, a este respecto, que la Sociedad Antropológica Española fundada en 1865 por el Dr. González Velasco, tenía por objeto 
el estudio de la historia natural del hombre y las ciencias que con ella se relacionan; para ello se dividió en cuatro secciones: Filosofía, Historia, Fisiología y Ciencias Físico-Químicas (Estatutos, 1865: 9), sin que ello resultara chocante a sus socios-, el acuerdo por delimitar la disciplina frente a otras ciencias, y, sobre todo, la búsqueda común de un reconocimiento social e institucional, proporciona unidad a esa antropología del siglo XIX. Lo que quiero decir es que una ciencia no sólo alcanza acuerdos fundamentales entre sus practicantes cuando éstos comparten un paradigma, sino que también en situaciones preparadigmáticas, existen éstos, aunque reducidos a su mínima expresión. Hoy en día, por ejemplo, todas las escuelas antropológicas "coinciden en el reconocimiento de la cultura como factor clave en la explicación del hombre y en el rechazo de los métodos introspectivos y etnocéntricos en el estudio del ser humano" (García, 1979: 261). Las concepciones opuestas de lo que ha de ser la disciplina no son obstáculo, en definitiva, para que las distintas tendencias estén de acuerdo en lograr el mayor desarrollo institucional posible, lo cual implica el reconocimiento académico, social, político, dotación económica, etc.

Algunos paradigmas antropológicos, como el funcionalismo de Radcliffe-Brown (1975) en el pasado, o el materialismo cultural de Marvin Harris (1982) en la actualidad, han pretendido convertir a la antropología en una disciplina similar a las ciencias físicas o naturales, sin que por ello puedan, a su vez, ser equiparados. En otras ocasiones, como en el caso de Evans-Pritchard (1978: 46), se ha incluido a la antropología dentro de las ciencias humanas o sociales, intentando emparentarla con la historia. Estos desacuerdos sobre qué sea la antropología se dan, por tanto, a nivel de paradigmas. En la medida en que los paradigmas no son objeto de refutación, como lo pueda ser una teoría, su rechazo o elección frente a otros no puede tener lugar en base a las propias teorías científicas que conllevan. Si los criterios científicos no son suficientes para decidir entre paradigmas, corrresponderá a la filosofía decidir qué modelo ofrece mayores ventajas a las necesidades de la ciencia en cada momento. Por tanto, la antropología filosófica, en tanto que epistemología de la antropología, deberá denunciar lo que de erróneo pueda haber en los distintos paradigmas, sus limitaciones y las ventajas que ofrecen a la investigación.

Pero no es sólo la tarea de comparación interparadigmática la que corresponde ejercitar al antropólogo filosófico. Como estudioso de las teorías antropológicas deberá analizar también las teorías y hechos que cada paradigma lleva consigo. La conexión entre unas y otros, la coherencia entre las teorías que componen el paradigma, la sencillez de las mismas, su posible rendimiento, su capacidad explicativa, los problemas 
que presenta y los objetos que escapan a su explicación, serán otras tantas preocupaciones para el pensamiento filosófico.

Poner de manifiesto los elementos que están ocultos entre los supuestos de cada paradigma o discutir acerca de la adecuación de una teoría, es una tarea propia de la antropología filosófica como disciplina, pero eso no quiere decir que sea exclusiva de los filósofos. Es evidente que todo profesional de una disciplina está capacitado para pensar acerca de los fundamentos de la ciencia que conoce. Antropólogos o filósofos, lo cierto es que cuando se trata de la teoría antropológica ambos tienen mucho que decir. Sin embargo, debe quedar claro que lo que diga un antropólogo de la epistemología de su disciplina lo dirá en tanto que filósofo, no como antropólogo. Obras como El materialismo cultural de Harris (1982), o la más antigua Fundamentos de antropología social de Nadel, pueden figurar en cualquier biblioteca como libros de antropólogos que han decidido pasar revista a los fundamentos de su profesión, pero, por eso mismo, hay que considerarlos como teóricos de la ciencia, como filósofos cuyo análisis se vuelca hacia su propia ciencia.

No se puede minusvalorar la importancia que la epistemología tiene para el desarrollo de cualquier disciplina, pero ésta es trascendental en ciencias humanas. La posibilidad de conseguir una ciencia paradigmática, lo cual no quiere decir que ésta deba tener un estatuto epistemológico similar a las ciencias físicas, no la proporciona la acumulación de información y la repetición de investigaciones, sino la articulación de éstas dentro de nuevos moldes. Esta perspectiva sólo pueden alcanzarla las ciencias humanas mediante la discusión sobre los fundamentos de su teoría. Pero, además, el uso de la antropología filosófica como epistemología de las ciencias humanas no debe ser considerado un añadido a la tarea del antropólogo. No hay una actuación del antropólogo como estudioso de otras culturas, y una fundamentación de su disciplina por parte de los filósofos o de antropólogos que actúan como tales. La acumulación de datos como producto del trabajo de campo y su posterior estructuración dentro de teorías que los interpreten no puede ser entendida como un proceso que consta de dos fases; sólo el empirismo más recalcitrante puede ignorar que no existen los hechos puros, sino que éstos sólo adquieren sentido dentro de determinadas teorías, y éstas, a su vez, se justifican mediante la adecuada selección de los hechos. El antropólogo debe llevar a cabo su tarea imbuido de una filosofía, sobre todo, porque la supuesta ausencia de ésta no deja de ser una de las más peligrosas filosofías que cabe mantener (Gusdorf, 1968: 1792).

Existe, por último, pero no menos importante que las anteriores, una tarea donde la antropología filosófica, también entendida como metodo- 
logía, puede contribuir al desarrollo de la antropología. Es lo que afecta a la historia de ésta. La investigación sobre la génesis de la disciplina en el pasado es esencial para determinar hasta qué punto ésta ha avanzado en la explicación de los problemas que aborda. Tal investigación ofrece, por tanto, dos vertientes, la primera de las cuales mira al pasado: exponer los distintos momentos de su racionalidad científica en la correspondiente matriz social"; mientras la segunda afecta claramente al presente: "demostrar sus implicaciones directas en la teoría social contemporánea" (Llobera, 1980: 17).

Enunciados de la manera anterior ambos objetivos parecen, a la par, accesibles e independientes. Pero, en la práctica, la investigación sobre el pasado de la antropología no ha podido desprenderse de los intereses del presente desde el que tenía lugar la búsqueda. Debido a esta circunstancia, al igual que no hay hechos sin teoría ni teoría que no proponga sus propios hechos confirmatorios, la historia de la antropología tampoco ha podido establecerse como un campo neutral. La mayor parte de las ocasiones no es otra cosa que el repertorio de autores que la escuela a la que pertenece el historiador quiere imponer. La manipulación a la que se prestan este tipo de historias es total. La historia basada en estas premisas no sirve para establecer una auténtica historiografía; en realidad, sólo puede considerarse el reflejo de las disputas metodológicas entre las distintas escuelas antropológicas. El progreso que muestran estas historias tiene como objetivo final demostrar que el último logro de la disciplina, y acaso el más importante, es el que aporta la línea metodológica del que hace la historia (Castilla, 1990). No hace falta decir que la acumulación de historias de este tipo no favorece, en absoluto, el auténtico conocimiento de lo que ha sido el contexto en el que surgió la antropología y las polémicas en torno a las cuales se gestó el núcleo de problemas que con el tiempo la originarían. Una historia que escribe el pasado desde el punto de vista de sus intereses presentes no puede darnos nunca la clave de lo que realmente ocurrió en el pasado. Pero tampoco sirve esta historia para el segundo de los objetivos que hemos enunciado, pues es patente que nunca podremos estar seguros de las implicaciones que pueda mostrar con la teoría antropológica actual. Una historia que se desee unir interesadamente a nuestro presente deberá ser escrita descle presupuestos de escuela; si se quiere alcanzar una historia de la antropología en la que el pasado sea investigado con la clara intención de conocer ese pasado, los valores que guíen su realización deberán ser lo más objetivos, aunque no asépticos, posible. Esta tarea deberá ser realizada por quien posea una buena formación histórico-filosófica, pues su vinculación con la historia del pensamiento o con la historia de las ideas resulta clara. Con ello no se 
quiere decir que los antropólogos estén excluidos de escribir su propia historia, lo que se afirma es que el mero hecho de ser antropólogo no es suficiente si queremos ir más allá de una historia cuyos relatos no soportan una mirada crítica. Quisiera, finalmente, advertir que una perspectiva que pretende ser objetiva no debe entenderse como algo uniforme, aséptico o falto de compromiso. La objetividad es un ideal que se tiene presente, pero dentro del mismo caben interpretaciones diversas; sólo la confrontación determinará cuáles de ellas son mejores o peores. El historiador no renuncia a sus sentimientos ni a las hipótesis, suponiendo que ello fuera posible, pero no intenta forzar la interpretación de los hechos para que coincidan con ellas. Tampoco olvida que su compromiso primero e irrenunciable es con la verdad, y a su búsqueda se encamina. No se debe olvidar, en definitiva, que las ideas filosóficas son múltiples, por tanto, decir que una investigación debe ser histórico-filosófica o crítica, quiere decir que debe contar con el requisito previo de objetividad deseable, no que ésta renuncie por completo a valores, hipótesis, teorías, etc. La diferencia entre una historia de escuela y una historiografía objetiva estriba en el grado de comprensión hacia su objeto, que es ficticio en el primer caso. Pero, sobre todo, se encuentra en el nivel de autoconciencia que se posee para reconocer lo que puede haber de añadido personal en las conclusiones que se vayan obteniendo.

Francisco Castilla Urbano

I.E.S. Luis Braille, Madrid

BIBLIOGRAFÍA

\section{A) ESPECIFICA}

BUENO, G., 1987: Etnologia y utopia, Barcelona: Júcar [1971].

CASSIRER, E., 1977: Antropología filosófica, México: FCE [1944].

Castilla Urbano, F., 1990: "La historia de la antropología como excusa: la influencia de la metodología en la disparidad historiográfican, RDTP, XLV, 21-41.

CHOZA, J., 1985: Antropologias positivas y antropología filosófica, Tafalla (Navarra): Cénlit ediciones.

Esteva Fabregat, C., 1972: Antropologia y filosofia, Barcelona: A. Redondo.

- 1982: "Autobiografía intelectual de...", Anthropos, 10 (marzo), 4-25.

EVAns-Pritchard, E. E., 1978: Ensayos de antropología social, Madrid: Siglo XXI [1962].

GARCiA GARCiA, J. L., 1979: :La antropología y el estudio general del hombre,, en J. DE SaHaGún (ed.), Antropologias del siglo XX, Salamanca: Sígueme, 259-274.

GEHLEN, A., 1980: El hombre. Su naturaleza y lugar en el mundo, Salamanca: Sígueme [1940]. 
GuSDORF, G., 1968: -Ethnologie et métaphysique: l'unité des sciences humaines", en J. POIRIER (ed.), Etbnologie generale, Paris: Gallimard-Encyclopedie de la Pleiade, 1772-1815.

HARRIS, M., 1982: El materialismo cultural, Madrid: Alianza [1979].

LEACH, E., 1970: Lévi-Strauss, antropólogo y filósofo, Barcelona: Anagrama [1965].

LÉvi-STRAuss, C., 1964: El pensamiento salvaje, México: FCE [1962].

LLOBERA, J. R., 1980: Hacia una bistoria de las ciencias sociales, Barcelona: Anagrama.

MORENO, I., 1979: Cultura y modos de producción. Una visión de la antropología desde el materialismo bistórico, Madrid: Edit. Nuestra Cultura.

NADEL, S. F., 1974: Fundamentos de antropologia social, Madrid: FCE [1951].

RADCLIFFE-BROWN, A. R., 1975: El método de la antropología social, Barcelona: Anagrama [1958].

RODRíguez MOLINERO, J. L., 1977: Datos fundamentales para una bistoria de la antropología filosófica, Salamanca: Univ. Pontificia.

RONZÓN, E., 1991: Antropología y antropologias. Ideas para una bistoria crítica de la antropología española. El siglo XIX, Oviedo: Pentalfa Ediciones.

SAN MARTín, J., 1988: El sentido de la filosofía del hombre. El lugar de la antropología filosófica en la filosofía y en la ciencia, Barcelona: Anthropos.

SARTRE, J. P., 1970: Crítica de la razón dialéctica, Buenos Aires: Losada [1960].

SCHELER, M., 1970: El puesto del hombre en el cosmos, Buenos Aires: Losada [1928].

SOCIEDAd ANTropológica ESPAÑola, 1865: Estatutos y Reglamentos de la..., Madrid.

\section{B) GENERAL}

BUBER, M., 1949: ¿Qué es el hombre?, México: FCE [1942].

CORETH, E., 1976: ¿Qué es el bombre? Esquema de una antropologia filosófica, Barcelona: Herder [1973].

FARRÉ, L., 1968: Antropología filosófica. El bombre y sus problemas, Madrid: Guadarrama.

FERRATER MORA, J., 1962: El ser y la muerte, Bosquejo de filosofía integracionista, Madrid: Aguilar (ed. corregida: Madrid. Revista de Occidente, 1967).

GADAMER, H. G., 1977: Verdad y método, Salamanca: Sígueme [1965].

GARCíA BACCA, J. D., 1982: Antropología filosófica contemporänea, Barcelona: Anthropos [1955].

GRANELL, M., 1969: La vecindad bumana, Madrid: Revista de Occidente.

GroethuYsen, B., 1951: Antropología filosófica, Buenos Aires: Losada [1931].

HeIDEgGer, M., 1973: Kant y el problema de la metafísica, México: FCE [1929].

Jouf, J. Y., 1969: Comprender al bombre, Salamanca: Sígueme [1967].

КАмLAн, W., 1976: Antropología filosófica y ética, Buenos Aires: Alfa.

LANDmanN, M., 1961: Antropología filosófica, México: Uteha [1955].

LORITE MENA, J., 1982: El animal paradójico. Fundamentos de antropología filosófica, Madrid: Alianza.

MARfAS, J., 1970: Antropologia metafísica, Madrid: Revista de Occidente.

MUGA, J. y CABADA, M. (eds.), 1984: Antropología filosófica: planteamientos, Madrid: Luna.

SAHAGúN, J. DE (ed.), 1976: Antropologias del siglo XX, Salamanca: Sígueme. 
En este artículo se considera que las relaciones entre filosofia y antropología han sido con frecuencia analizadas de forma interesada. Esta actitud ha perjudicado no solo a estas dos disciplinas sino también a la antropología filosófica, la historia y la espistemología de la antropología, que son los dominios donde aquéllas deberían encontrar su mejor punto de convergencia. En consecuencia, se intenta establecer un marco de colaboración que resulte beneficioso para todas estas disciplinas.

It is considered in this article that, very often, the relationship between philosophy and anthropology have been analysed in a biased way. This attitude has been detrimental not only to these disciplines, but also to the philosophical anthropology, history and the epistemology of anthropology, which are the study fields where those should find their larger point of concurrence. Accordingly, we try to establish a framework of collaboration which would prove to be profitable for all of them. 